\title{
Primary conjunctival peripheral T-cell lymphoma: a case report.
}

\author{
Safae AStati ${ }^{1}$, Mohamed Allaoui ${ }^{1}$, Mohamed Mikdame ${ }^{1}$, and kamal doghmi ${ }^{1}$ \\ ${ }^{1}$ Mohammed V University of Rabat
}

August 8, 2021

\begin{abstract}
Primary ocular adnexal T-cell extranodal lymphoma are uncommon and carry a particularly poor prognosis. It represents $1 \%-2 \%$ of all NHL. Because of its rarity, we want to show to the medical community our experience about primary conjunctival $\mathrm{T}$ cell lymphoma by reviewing literature and discussing our case.
\end{abstract}

\section{Introduction :}

Primary orbital/ocular adnexal T-cell extranodal lymphoma are uncommon and carry a particularly poor prognosis, with a high predilection for systemic dissemination. Data on these lymphomas is poor [1]. Because of its rarity, we want to show to the medical community our experience about primary conjunctival $\mathrm{T}$ cell lymphoma by reviewing literature and discussing our case.

\section{Observation :}

A 46-year-old male presented at our formation with a 3-month history of ocular symptoms. He complained of feeling of sandy sensation in the eyes, ocular redness then swelling of the lower eyelid with general symptoms. This symptomatology was not improved by local treatments.

At physical examination, visual acuity was 10/10; a light reflex retained a right proptosis and swelling of the right lower eyelid with significant chemosis. The fundus was normal.

Laboratory results showed normal blood count. Serum tests revealed that LDH was 535 UI/L, $\beta 2$ microglobulin: $2.02 \mathrm{mg} / \mathrm{L}$, with normal both renal and hepatic functions.

Histopathology of the conjunctival biopsy revealed diffuse, heterogeneous lymphoid proliferation with arborizing epithelioid venules. Immunohistochemistry showed that the neoplastic cells express LCA, CD3, CD43 and CD45, and negative expression for CD20, CD21, CD23, cytokeratin, myogenin and vimentin (figure 2).

Chest, Abdomen and Pelvis CT and brain CT were normal. The bone marrow biopsy showed no lymphoma infiltration. To sum up, our patient had a primary conjunctival peripheral T-cell lymphoma.

The patient successfully received four courses of chemotherapy with cyclophosphamide, doxorubicin hydrochloride, vincristine, and prednisone.

Fifteen days after the fourth course, the patient presented with left facial paralysis and monoplegia of the left arm and right leg. Physical examination revealed glove and stocking hypesthesia and absence of deep tendon reflexes. The plantar reflex was normal. The brain CT (with contrast) was normal. A lumbar puncture was performed. The cerebrospinal fluid protein (CSF) concentration was increased at 3,29g/l. The cytology CSF confirmed the diagnosis of leptomeningeal lymphoma. The patient received a high-dose intravenous methotrexate with intrathecal chemotherapy. At the 30th day of follow-up, the patient died because of a septic shock. 


\section{Discussion :}

Ocular adnexal lymphoma (OAL) is a rare manifestation of non-Hodgkin's lymphoma (NHL). It represents $1 \%-2 \%$ of all NHL and 5\%-10\% of all extranodal lymphomas [2]. About 25\%-30\% of OALs involve the conjunctiva [2]. Conjunctival lymphomas are most commonly extranodal marginal zone lymphoma [previously termed mucosal associated lymphoid tissue (MALT)] (68\%), follicular lymphoma (16\%), mantle cell lymphoma (7\%), and diffuse large B-cell lymphoma (5\%). Whereas the T-cell and T/natural killer-cell lymphoma type are rare and very aggressive; this subtype presents only $1 \%$ to $3 \%$ of all lymphomas in these sites [3]. Up to $80 \%$ of T-cell NHL in the conjunctiva appear as secondary lymphomas [4].

Few cases of primary orbital peripheral T-cell lymphoma were reported in literature [5-9] (Table 1). Clinical features of conjunctival lymphoma are non-specific and the lesions can look nearly identical to other more benign processes. Biopsies and further studies are fundamental to make the diagnosis. Our case was an unusual site of $\mathrm{T}$ cell lymphoma; thus, the diagnosis was totally unexpected. As well as the patient did not have the widespread and systemic disease symptoms frequently associated withthis type of lymphoma. There by careful histopathological examinationis very important for prompt confirmation of the diagnosis and early commencement of treatment. However, patients should have a complete medical check and an extented evaluation of the systemic disease. There is no consensus on the treatment of these lymphomas. The management of conjunctival lymphoma relay on location, extent of periocular involvement, systemic staging of the disease, and general health of the patient [10]. The Modalities include complete surgical resection if possible; external beam radiotherapy and specifc systemic chemotherapy protocols. We opted for the last strategy in our case because the data is scarce. He was treated by CHOP chemotherapy (cyclophosphamide, doxorubicin, vincristine, prednisone). T-cell lymphoma is considered extremely rare in conjunctiva with poor prognosis. Approximately, half of patients progress or relapse during the first year after diagnostic [7]. Our case illustrates the unfavorable evolution and the aggressiveness of the disease with meningeal relapse during the treatment. The patient died within 4,3 months of diagnosis.

\section{Conclusion:}

T-cell lymphomas are rare but should still be kept in the differential diagnosis of orbital lesions. In our case, the diagnosis was totally unexpected. The diagnosis is mostly histological, hence the interest of careful histopathological examination by an experienced pathologist. Given its rarity, the therapeutic strategy must be discussed case by case in a multidisciplinary consultation meeting.

\section{References :}

[1] Tanenbaum, R.E., Galor, A., Dubovy, S.R. et al. Classification, diagnosis, and management of conjunctivallymphoma. Eye and Vis 6, 22 (2019).

[2] Sjö LD. Ophthalmic lymphoma: epidemiology and pathogenesis. Acta Ophthalmol 2009;87 Thesis 1(Thesis 1):1-20.

[3] Al-Muammar A, Hodge WG, Farmer J. Conjunctival T-cell Lymphoma: A Clinicopathologic Case Report. Ophthalmology 2006; 113: 459-61.

[4] Kirkegaard MM, Coupland SE, Prause JU, Heegaard S. Malignant lymphoma of the conjunctiva. Surv Ophthalmol. 2015;60(5):444-58.

[5] Chen YJ, Chen JT, Lu DW, Gao HW, Tai MC. Primary Peripheral T-Cell Lymphoma of the Orbit. Arch Ophthalmol. 2009;127:1070.

[6] Janatpour KA, Choo PH, Lloyd WC. Primary orbital peripheral T-celllymphoma: histologic, immunophenotypic, and genotypic features. Arch Ophthalmol. 2007;125:1289-92. (Chicago, Ill. 1960).

[7] Al-Muammar A, Hodge WG, Farmer J. Conjunctival T-cellLymphoma: A Clinicopathologic Case Report. Ophthalmology 2006; 113: 459-61. 
[8] Lee DS, Woo KI, Chang HR. T-cell lymphoma presenting as painful ophthalmoplegia. Korean J Ophthalmol. 2006;20:192-4.

[9] Coupland SE, Foss HD, Assaf C, Auw-Haedrich C, Anastassiou G, Anagnostopoulos I, Hummel M, Karesh JW, Lee WR, Stein H. T-cell and T/ natural killer-cell lymphomas involving ocular and ocular adnexal tissues: aclinicopathologic, immunohistochemical, and molecular study of seven cases. Ophthalmology. 1999;106:2109-20.

[10] Shields, C.L.; Chien, J.L.; Surakiatchanukul, T.; Sioufi, K.; Lally, S.E.; Shields, J.A. Conjunctival Tumors: Review of Clinical Features, Risks, Biomarkers, and Outcomes - The 2017 J. Donald M. Gass Lecture. Asia Pac. J. Ophthalmol. (Phila) 2017, 6, 109-120.

[11] Kirkegaard MM, Coupland SE, Prause JU, Heegaard S. Malignant lymphoma of the conjunctiva. Surv Ophthalmol. 2015;60(5):444-458

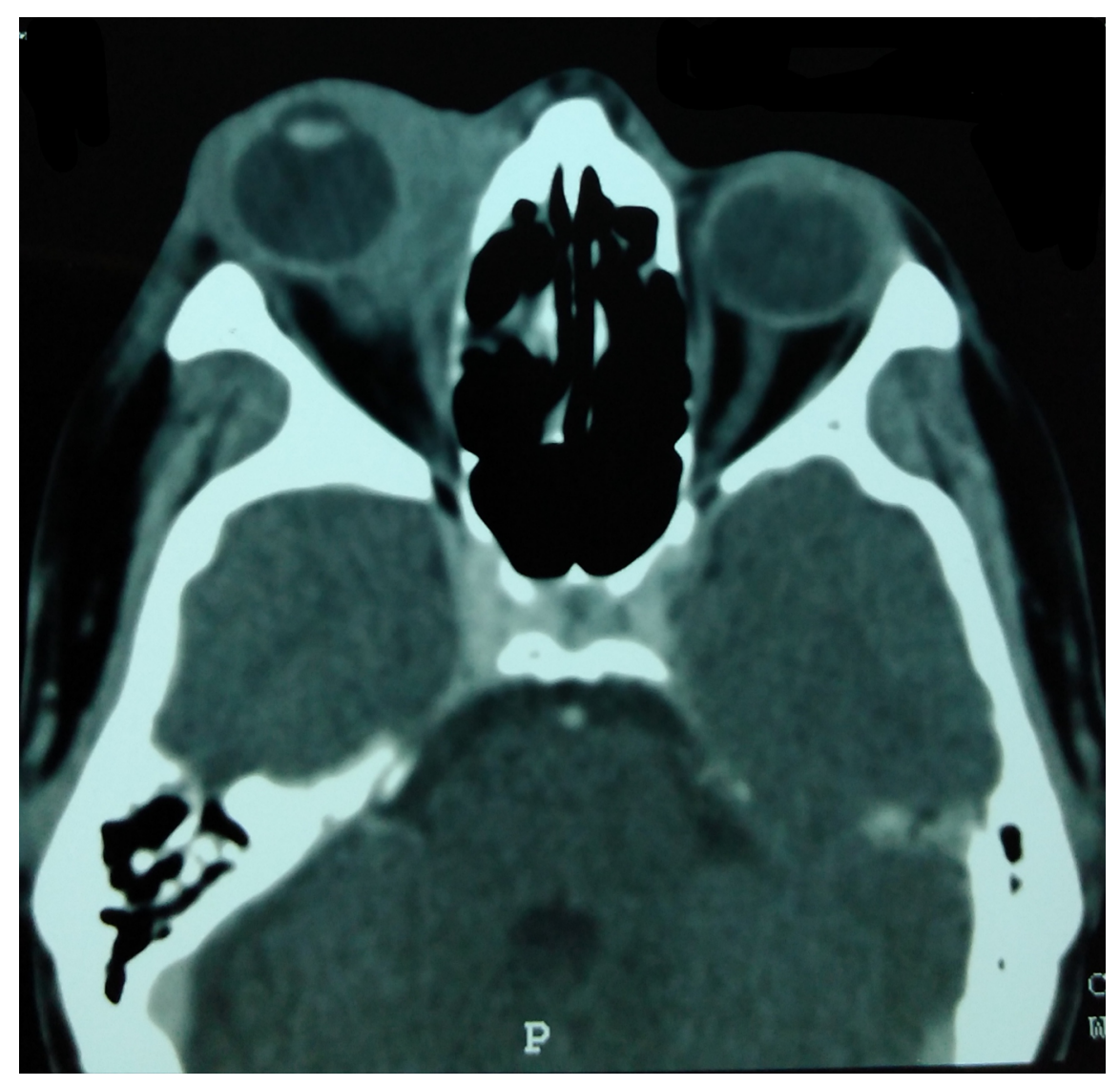

\section{Hosted file}

figure 2.docx available at https://authorea.com/users/429711/articles/533331-primaryconjunctival-peripheral-t-cell-lymphoma-a-case-report

\section{Hosted file}

table 1.docx available at https://authorea.com/users/429711/articles/533331-primaryconjunctival-peripheral-t-cell-lymphoma-a-case-report 